\title{
China's FDI Impact on Economic Development in the Developing Countries in Africa (The Case Study of Comoros)
}

\author{
Abdillah Slim ${ }^{1}$, Du Xuejun ${ }^{2}$, Cheng Fangfang ${ }^{3}$ \\ School of Economics and Management, Zhejiang University of Science and Technology; Hangzhou, CN \\ slims96abdillah@gmail.com
}

\begin{abstract}
China's continued development assistance to Africa in recent decades is one of the most controversial events in the region. China's aid to Africa, fueled by the spirit of the growing self-secession of African countries, has attracted the world's attention. While friends see the great help as a lucrative opportunity for both sides, the enemies of the association fear the potential impact of Chinese development aid on increasing their own stoic capacity. Despite the growing debate between friends and enemies of these associations, little existing literature has examined the sincerity of China's capacity-building assistance, focusing on job creation and technology or ICT transfer. There is a lack of clear evidence of capacity building indicators, such as job creation and technology transfer. In the absence of literature, this study tries to emphasize and examine China's impact on the construction of chamber capabilities in job creation and technology transfer. The study used key data from semi-structured interviews that included open questions and secondary data, such as the White Paper in China. Unlike previous studies in Angola, Sudan and Uganda, the situation in the Comoros is quite the opposite. The results paint an image of the impact of support for the Chinese project on the construction of capacities in the Comoros, which at best remains "negligible." The country can reach its full potential and there is an urgent need to restore the political and economic power of Comoros.
\end{abstract}

Keywords: Aids, Economics, Foreign Direct Investment, Comoros, China-African, Developing Countries

DOI: $10.7176 / \mathrm{EJBM} / 12-27-16$

Publication date:September $30^{\text {th }} 2020$

\section{Introduction}

This excerpt from China's Foreign Ministry spokesman, Jiang Yu's response to a joint question-and-answer session following recent criticism of China's foreign policy and commitment in Africa, in which he described China's assistance in Africa as a trust booster, captures the main reason for this investigation. This issue has also caught up with my interest in launching controversial debates and discussions in academic, media and political circles on the nature of development aid by China, to African countries, which are the main beneficiaries, the cause of this aid and the impact of this aid on the beneficiary countries. This has finally led to the abundance of literature with polarized ideologies in this area of controversy. While Taylor (2004) agrees that the main impetus behind China's interest in Africa is economic and diplomacy, Shelton (2001) represents China's commitment to Africa, driven by the three main strategic interests; Africa offering ready-to-market Chinese products, resource gap, and oil that beautifies China's rise. China plans to hide the imperialist formulation toward the African counterpart in order to embed all dividends on the way, according to Rupp (2008).

On the other hand, some scientists, as well as officials from most recipient countries and Chinese government officials, are destroying this China - Africa relationship. Alternatively, viewing China's assistance to Africa from the point of view of interdependence, there are claims that China's development aid offers a lucrative opportunity for both sides. Although previous investigations into cases such as Sudan, Angola and Uganda have spurred some boost in capacity building because they are committed to China, the Comoros case was different. The results of the Comoros case show the impact of Chinese project support on capacity building in the Comoros, which is at best "negligible". Unlike the cases in Sudan and Uganda, which have some impetus to develop capacities because of their relations with China, the same could not have been done to help the Comoros.

\subsection{Statement of Problem}

Like most other typically developing and African economies, Comoros' economy relies heavily on a large influx of foreign aid. Different from the traditional aid donors, China's aid in most cases are intended for grandiose projects such as Sporting Complexes, Friendship Halls just to name a few and it comes with some conditionality. 
This conditionality as well as the general formalities such as the principle of non-interference that surrounds China's aid to these recipient countries engulfs the part of the problem addressed in this research. One of such conditionality that has greatly attracted my interest and it is my responsibility to research is the fact that most of the implementation and constructions of these projects are mostly carried out by Chinese companies. With the implementation process of most of these aid projects effectuated by Chinese companies, it has developed a huge debate for critics, over the continuous utilization of Chinese labour and input by these companies, which undermines the economic prospect of its relation with the recipient country. With such undermining prospect, critics such as renowned African economist George Ayittey, have questioned the rhetoric of China's aid being a capacity builder when the nature of these aids deal are not transparent, their impact on local economies is outrageous and they offer scanty employment opportunities to the recipient countries such as the case of Uganda. With that in mind, this research will seek an in-depth case analysis of impact of this China's development aid towards capacity building of Comoros, while hoping that the findings from this research will assist academicians and politicians to design policies to enhance Sino - African relationship.

\subsection{Research Questions}

Fascinated by the perspectives of actors who use a realistic approach to describing China, Africa's partnership undermines Africa's capacity-building in the Chinese principle without interference in issues that significantly undermine human rights, good governance, democracy and the continued use of Chinese workers and have not documented any information detailing their aid relationships, I am very excited to explore the empirical basis of the impact of these subsidies on economic development. In this respect, I anticipated this research question to be answered: How does Chinese aid contribute to capacity building in Comoros in job creation and Technology or ICT transfer?

\subsection{Significances of Study}

The research is a bit of an attempt to add to the ongoing conversation and debate in academia on various issues surrounding China's support for Africa. The document will examine China's assistance in one country and contribute to further literature that can be used, unlike other host countries. Moreover, I hope that by encouraging quest and interest for this research we can finally recruit more brains to ask really relevant and interesting questions about the current situation surrounding China's honeymoon with Africa.

\subsection{Literature Review}

\subsection{Comoros Economic Development Overview}

The Comoros archipelago is located in the Indian Ocean, north of the Mozambique Channel and northeast of Madagascar. While the spread of the virus in the Comoros so far appears to have been contained, economic activity has slowed sharply prior to the COVID-19 pandemic (coronavirus).

The current submissions of the EUP in the Comoros remain marginal, despite tax breaks and benefits offered by the Government, which aims to resolutely improve the climate and institutional stability of the country. According to UNCTAD's World Investment Report 2020, FED bookings in 2019 were only $\$ 8$ million, which is in line with historical trends, but well below the exceptional peak in 2011 (EUR 23 million). AED shares remain low despite an increase in 2019, estimated at \$129 million. The agricultural and fisheries sectors receive the largest share of foreign investment. The main investment countries are France, the United States and South Africa.

Comoros ranked 160 of the 190 countries in the World Bank's Doing Business Report 2020, gaining four places compared to the previous year. In May 2018, the African Development Bank approved a payment of USD 1.5 million for a support project from an investment promotion agency (PAAPI). Comoros' investment code does not provide an explicit definition of EDI and the regulatory environment continues to impose significant burdens on investors. However, the government is determined to reform the investment code and establish a single point of contact for the creation of a company. Poor infrastructure quality, limited internal market size, geographical isolation, frequent water and electricity shortages, limited natural resources and unseeded labour are also hampering EDI. In addition, property rights are not well protected and contracts are applied weakly. The legal system, based on both Sharia (Islamic) law and the French legal code, is weak and under political influence. Corruption is reported at all levels of government and exacerbated by internal political disputes and competition for resources between the administrations of the three islands. China is the country's largest investor. Over the past 
decade, the Chinese have invested millions in the country. They paved roads, built new schools, mosques, markets, government buildings (including the parliament building), a new airport, a centre to facilitate tourism and a sports stadium. In addition, China regularly sends doctors to the islands and builds a 12-million-dollar hospital.

Table 1: Comparing protection of investors according to countries

\begin{tabular}{|l|c|c|c|c|}
\hline & Comoros & Sub-Saharan Africa & United States & Germany \\
\hline Index of Transaction Transparency* & 7.0 & 5.0 & 7.4 & 5.0 \\
\hline Index of Manager's Responsibility** & 1.0 & 4.0 & 8.6 & 5.0 \\
\hline Index of Shareholders' Power** & 5.0 & 5.0 & 9.0 & 5.0 \\
\hline Source: Doing Business - 2016. & & & & \\
\hline
\end{tabular}

Note:

*The higher the index, the more transparent the terms of the transactions.

**The higher the index, the more the manager is personally responsible.

$* * *$ The higher the index, the easier it will be for shareholders to take legal action.

$* * * *$ The higher the index, the higher the level of protection for investors.

\subsection{China Foreign Aid to Africa}

China's official development financing in Africa consists mainly of interest-free grants and loans, debt relief and soft loans, as well as preferential export loans, commercial loans and loans from Chinese banks. Subsidies (rarely granted as budget aid) and interest-free loans were the main instruments of the ODA granted by China until 1995, when soft loans were introduced (Brautigam, 2011). China oversees aid and delivery of most of China's external finance. Both banks act as part of the Beijing Toolkit to support China's development goals (Brautigam, 2011). Despite this criticism, researchers like Davies et al. (2008) acknowledge the controversial role Chinese aid plays in Africa, but they portray China's role in economic development in recipient countries like Angola and Sudan. They described China's continued relationship with both Angola and Sudan as mutual benefit. The government's policy of reducing the number of people living in poverty is a major challenge.

While Guloba et al. (2010) research on China's assistance to Uganda further cradles some of the great positive effects of Chinese aid to Uganda, they however went on to highlight some major concerns about China's assistance to Uganda, which includes marginal employment of locals and the continued exploitation of Chinese foreigners, where these projects are being implemented. Nevertheless, their results show that China's assistance, which is mainly in the form of technical assistance through training in Chinese institutions, grants, interest-free loans, preferential loans, debt relief, have all gone a long way to reducing Uganda's external burden and thus has had a positive impact on the well-being of the people of Uganda. Wang et. al (2010) further delineates such positive effects of Assistance to China by referring to significant funding for multi-purpose development projects in sectors such as electricity (hydropower) and transport (railways and motorways), which are sectors in beneficiary countries that attract relatively little help from traditional donors. However, very few studies in Comoros literature have focused on the impact of Chinese FDI to the Comoros.

\subsection{Conceptual Analysis}

For nearly five decades, several wealthy donors have provided aid to African countries. The motive for such assistance ranges from various development, economic, commercial and political perspectives that seek mutual benefit for both donors and recipients. However, these aid measures normally cover all financial transaction agreements between one government or actors to another.

It is undeniable that, on the basis of the above definition, aid links will include the transfer of funds, the supply of goods, projects, programmes, construction and debt relief to the recipient countries. In fact, foreign aid has become a focus and locus in the recipient countries (Aluko \& Arowolo, 2010). This view eventually led to donor countries eventually being confirmed as a foreign policy equipment used to support and spread their influence over the beneficiary countries, which gave their role as the center to strengthen the definition of foreign aid to the OECD. 
This mindset is largely confirmed with the ideologies of Bretton Wood's institution. But with China becoming visible as a viable aid donor in Africa, the aid paradigm seems to be undergoing a make-over.

\subsection{Theoretical Framework}

A plethora of approaches and theories has thrived within the academic and political parameters to explain aid effectiveness. Ranging from Classical Realism, Dependency theory, Constructivism, Geopolitics theory, Globalism, Idealism and Imperialism, just to name few, all have sought to achieve a scientific explanation of the controversies surrounding aid effectiveness. Nonetheless, this research will adopt the Interdependence theory and the Political Realism which are two opposing theoretical views, predominantly employed by actors to explain the nature of the relation between China and Africa.

Interdependence theory is a broad and complex theory that was postulated during the 1970's, when the Political Realist perspectives on international relations was failing to take into account many of the new aspects of interstate relations (Brenner, 2000). Though the underlining settings of this theory have changed over time, the basic principles of this theory have remained the same. Interdependence is generally defined as mutual dependence between two entities. Created through the expansion of international transactions, with the benefits exceeding the cost, this description of Interdependence by Robert Keohane \& Joseph Nye greatly captures the current nature and scope of the China - Africa relation in accordance with the arguments postulated by friends of this relationship.

According to friends of this relationship, China - Africa relation is a reciprocal relationship where both actors are dependent on each other. Though the scope of the relationship is not similar i.e. China seeking raw material and market for its product and Africa seeking development assistance, both actors are simultaneously dependent on each other. Both actors can affect each other through their own resources i.e. China has the financial resources needed by Africa while Africa on the other had has the natural resources and the market needed by China. This perception greatly captures (Enuka 2011, p 44, 53) depiction of the China - Africa relations. He aptly portrays this relation as Interdependent whereby he depicts Africa as a poor and underdeveloped actor in search for financial resources and China as a relatively better off actor who is in dire need of raw materials, market and support. Thereby, implying that if China provides the financial and infrastructure resources needed by Africa, the spillover effect with eventually lead to increased employment creation and technology transfer which are all capacity building indicators, that depicts growth.

However, it is important to be mindful of the fact that, this reciprocal relationship must not necessarily be symmetrical. Though depicted as mutually dependent on each other, one should be careful not to assume that Interdependence is an evenly balanced relationship. Robert Keohane \& Joseph Nye (1977) used a very comprehensible example whereby actor $A$ maybe dependent on actor $B$ with respect to oil and actor $B$ maybe dependent on actor $A$ with respect to food. Though both actors are depending on each other, it is wrong to describe such a situation in which the control of actor $A$ over actor $B$ with respect to food is "balanced" by actor $B$ control of actor A with respect to oil.

Formulated in accordance to DAC member's personal principles and notion of socioeconomic development, aids issued out are intended to orient the recipient countries in the direction preferred by the donors. This ideology eventually prompted Hans Morgenthau (1962: p 309) to argue that "policy of foreign aid is no different from diplomatic or military policy or propaganda; they are all weapons in the political armory of the nation". In this respect, the motive of aid does seem to be mix political and economic desires of donors (Greber, 2012). This eventually implies that, despite their provision of aids, they actually do not lay emphasis on the impact towards capacity building in these recipient countries, but seek to promote their national interest.

\subsection{Methodology 3.0 Research Design}

It is doubtless that the research, with the above short description, will use a case study approach. As Yin (2003) aptly puts it, one should consider a case study design when the focus of the study is to answer how, when it comes to real-life behavior, that cannot be manipulated, when the contextual state of the phenomenon study is relevant, and also when the boundaries are not clear between this phenomenon and the context. These features are very linked to my research as I try to find out how China's help has affected the economic development of Comoros, 
which is a very relevant phenomenon to study.

With this in mind, I will employ a single research draft of the Case Study where the identifiable single case will be China, while the embedded entity in my research will be the Comoros. My choice of the only case lies in China's main role in providing foreign aid to African countries. After comparing the modern foreign aid index of the world's leading aid actors, I got to realize that China was one of the most plausible actors to investigate. With some prior research, I further realize that what can best serve my study and purpose is to find a particular country (embedded entity) that has received this foreign aid from China. When I started brainstorming about which country to choose from the many countries that receive foreign aid from China, it became almost impossible to choose a single country.

With the above criteria in mind, Comoros have made the above criteria very tailor-made. Moreover, the country's exogenous development strategy has contributed to its frenzied diplomatic relations with China, which has been limited by few official visits attended by top officials of both countries.

\subsection{Required Data Input}

With this in mind, my potential data sources, which led to my research on the above indicators, are both secondary and primary sources. Given that there are no secondary data that focus on China's capacity-building assistance, my main sources of secondary education are afforded official document analyses and mapping Chinese development aid in Africa and the European Development Research and Education Association (EADI) report on China's new presence in Africa. The accuracy and reliability of data/information from these sources is not managed by their source, as there is no possibility of this. But since they usually use formal and scientific materials in an academic environment, I trust them.

As for the primary sources that are the main data source for this study, I interviewed nine different outstanding players from different sectors of the Comoros by e-mail. Although the Comoros are a culturally diverse country based on my personal experience and personal observation, these nine interviewees largely represent the greater perception of most Comoros. This is because the interviewees were selected from key sectors, including the Comoros government official, opposition party, business, consultants, banking and financial institutions, national regulatory authorities and civil society.

But with such a drawback, I decided to conduct an interview with an email half-structured open questions that gives the interviewee space to fully formulate their answers. Given that there is a lot of criticism of the data obtained from interviews via email, such as the interviewer's not being able to read facial expressions and body language, make eye contact or hear the voice of the tone of the interviewee (visual and non-verbal signals), Denscombe $(2003, \mathrm{p} 51)$ recognizes that the quality of response achieved in online studies is the same as traditional methods. He said the same results were achieved in several studies that compared or conducted both email and face-to-face interviews. He also claimed that the interviewees in an email focused more on interview questions and offered more reflective close answers to their colleagues face-to-face. But that doesn't mean that the characteristics of face-to-face interviews are lower, but highlight the benefits of email interviews that give the interviewee time to be more thoughtful and careful about their responses compared to going to an interview with face-face.

\subsection{Findings and Discussions}

\subsection{Analytical Discussion}

This section of research provides an empirical analysis and evaluation of China's assistance in capacity building in job creation and technology transfer. This section covers and presents different results according to the topics. The general concerns and insights on the job creation indicator and topic 3 and topic 4 of the technology transfer indicator are highlighted. Although the second phase of these sections focuses on the analytical discussion of the results.

The analysis of evidence remains one of the least developed and difficult aspects of case studies (Yin, 2003). Marshal and Rossman (2011) assume that bringing order, structure and interpretation to the mass of collected data is messy, ambiguous, time consuming, creative, exciting and does not work linearly. However, I am primarily 
dependent on categorical aggregation techniques that offer linear and organized analyses of the collected data. It was the first postulate by Robert Stake (1995) as a technique used in case analysis, in which a scientist tries to collect case data in hopes of interpreting the relevant meaning of these cases. In addition, Creswell (2007) describes it as an informative method of drawing meanings across multiple instances of data.

To continue the data analysis, I design 4 categories representing the 4 main themes through which the data from the conversation is encoded by the indicators. These 4 categories are based on an understanding of the likely outcome of China's capacity building through the prism of political realism and interdependence. Forged by the notion that the politically realistic consideration of China's assistance to Africa is oriented toward Chinese interests, as explained above, the likely outcome of China's support for increasing job creation and technology transfer in the Comoros is irrelevant. While, on the other hand, forged the notion that interdependence theorists considered China's assistance to Africa for the mutual benefit of both sides, the likely outcome of China's assistance to increase job creation and technology transfer is significant.

However, it is important to pay attention to important and important averages, such as those used above. It is clear that Comoros are committed to employment opportunities and technology transfers because of the impact of these magnificent support projects in the Comoros. But the biggest question is how big or important these changes are worth paying attention to, which affects economic development. In this context, as is essentially used in the possible results of interdependent theorists, the changes within these two indicators show that they are worth paying sufficient attention to. The pointlessness used to describe the possible consequences of political realist theorists represents a change within these two indicators that is not worth considering.

Table 4.1 The Opinion of stakeholders.

\begin{tabular}{llll}
\hline \multirow{2}{*}{ Indicators } & \multicolumn{4}{l}{ stakeholders view of the effect of China's aid to Comoros } \\
\cline { 2 - 4 } & Political views & \multicolumn{3}{l}{ Interdependency views } \\
\hline \multirow{3}{*}{ Creation of Jobs } & Will lead to & Will lead to & significant \\
insignificant increase & increase & \\
\hline \multirow{2}{*}{ ICT Transfer } & $\begin{array}{l}\text { Will lead to } \\
\text { insignificant increase }\end{array}$ & increase & \\
\hline
\end{tabular}

This perception as defined above derives from politically realistic ideology. Unlike Topic, the ideology of interdependence, tries to find evidence within the data that depict china's help that it has enough jobs for the Comoros, which is worth considering. The third theme, formulated from a politically realistic ideology, looks to find evidence within the data that depict China's assistance as not having led to enough ICT transfer, which is worth considering. While other ideology of theoretical dependency, trying to find evidence within the data depicting China's assistance as it leads to enough technology transfer, this is worth considering.

As outlined above, the aim is to discover the kind of impact china has had in the Comoros (create jobs and transfer technology). I will try to draw cases from the data that I can evaluate in the context of analytically oriented indicators. It will greatly help to develop a converging line of evidence that will make my conclusions as strong as possible.

\subsection{Creation of Jobs: Findings and discussion}

Persistent poverty, increase income inequality and slow job growth further exacerbated by the ongoing financial and economic crisis faced by the traditional aid donors, are critical constraints on the socio-economic development of most African countries. Promoting job growth has and continuous to be a central challenge for most of the African countries. With the traditional donors faced with financial and economic crises, China has forged its way into the donor community by providing huge Project aid to the bulk of the African countries. However, with such grandiose projects, one will overwhelmingly expect a job booster within the recipient African countries. Though, in some cases such as the case of Sudan, these grandiose projects have booster employment creation. it was discovered that local residents only provided labour on a marginal scale while a substantial component of the 
workforce are Chinese. What thus the case of Comoros presents?

\subsection{ICT Transfer: Findings and Discussion}

The importance of technology transfer for economic development cannot be exaggerated. Acquiring technological skills and spreading them in the recipient countries, stimulating economic growth. This would be reflected in the case of Sudan, Uganda and Angola, which are examples of Africans who are best able to describe and assess their support relationship with China, have been largely successful in the field of technology transfer. With Chinese project support, the availability of physical capital (such as machinery and equipment, etc.) and raw materials has increased. In addition, a significant impact on the transfer of technology is the increase in Chinese education (internal and external) programs in these countries. Many citizens working on these Chinese aid projects will be trained simultaneously during the process of implementing Chinese aid and development assistance.

\subsection{Summary}

The above findings and analytical discussion in relation to China's aid towards Capacity building in Comoros, seems to be special. While other Africa countries boost of the positive impact of China's aid towards capacity building in their respective countries as anticipated by the Interdependency theorist, same cannot be said of Comoros. The following table provides a summary of findings.

Table 4.2 The Opinion of stakeholders.

\begin{tabular}{llc}
\hline \multirow{2}{*}{ Indicators } & \multicolumn{2}{l}{ stakeholders view of the effect of China's aid to Comoros } \\
\cline { 2 - 3 } & Political views & \multicolumn{2}{c}{ Interdependency views } \\
\hline Creation of Jobs & Strong arguments to support & Weak arguments to support \\
\hline ICT Transfer & Strong argument to support & Weak argument to support \\
\hline
\end{tabular}

It would be agreed from the table above that, according to the data, the impact of Chinese aid on capacity building in the Comoros was insignificant in light of job creation and ICT transfer. This finding strongly confirms the politically realistic ideology of the potential impact of Chinese assistance to the Comoros. As a portrait on the table above, the interviews gave very strong arguments. On the other hand, the arguments of respondents who considered that this assistance led to a significant increase in job creation and technology, as defined in topic 2 and 4, were weak in transmission. These findings nullify both hypotheses that lead to research. Aware that both hypotheses assumed China's assistance to the Comoros would lead to the creation of employment and technology transfer, this was not the case. Moreover, these findings not only nullify our hypothesis, but also provide us with a very clear answer to the research question about how China's support affects the Capacity building of the Comoros in terms of job creation and ICT transfer.

\section{Conclusion}

Indeed, it seems justified to say that few relationships have been so controversial, and still so promising and glued with potentials as that which glues China and Africa together. In many ways, the China - African relationship has raced through both high and low points - the continued use of Chinese workers, the unbalanced nature of the burgeoning trade ties continues to loom the psyche of Africans. Yet in many ways China and Africa need each other. For example, Health centers across most of the Comoros consist of sparsely equipped, cement block rooms. China regularly sends teams of doctors to the country, and it's building a $\$ 12$ million, modern, eight-story hospital. The Chinese are paving roads, building new schools, new mosques, new government buildings, a new airport, a center to facilitate tourism to the country and even new homes -- for politicians. Local TV and radio stations were designed and built by China, and four Chinese government-run television channels now pipe programming from Beijing directly into Comorans' homes. Late last year, China announced a $\$ 2$ million gift to the Comoros to build a new sports stadium. They all amount to very visible reminders of the nation's benefactors about 6,000 miles away in Beijing.

But the brief of this research was not only to examine the impact of Chinese aid FDI on job creation and ICT transfer, but research why the Comoros case was "exceptional" when most other African countries such as Angola, Sudan and Uganda all have experienced some impetus toward capacity building due to their relationship with China. From the interview, it is clear that corruption and the lack of an organization may be an internal reason 
why Comoros still finds a brief end to the development staff. In all, the study illustrates some limited Chinese exploration - the Chamber partnership in the light of the power building. Limited by the scope and acquisition of information, the investigation has only acquired highly relevant concerns about employment creation and technology transfer. I just request that I enrich the students and those who are interested in exploring some interesting complexities that reduce this partnership. I hope that wet Buddhist hunger, in the end, can recruit more minds dedicated to asking real relevant questions about China - chamber relations, which have been less explored so far

\section{References}

Aluko, Funso \& Arowolo, Dare. (2010) Foreign aid, Third World's debt crisis and implication for Economic development, African Journal of Political Science and International Relations Vol. 4(4) pp. 120-127.

Brautigam, D. (2008) China's Foreign Aid in Africa: What Do We Know? In: Rotberg, R.I (ed.) CHINA into AFRICA: Trade, Aid, and Influence. Washington D.C.: Brooking Institution Press., p.197 - 216

Davies, M. et al. (2008) How China delivers development Assistance to Africa. [online] Available at: http://www.ccs.org.za/downloads/china-dev-africa-sum.pdf (Accessed 07/05/2013).

Denscombe, M. (2008). The Length of Responses to Open-Ended Questions: A Comparison of Online and Paper Questionnaires in Terms of a Mode Effect Social. Science Computer Review Fall 200826: 359368

Enuka,Chuka (2011). Aid in Sino-African Relations: An Analysis of the Prompting, Pluses and Problems of China's Aid to Africa, The IUP Journal of International Relations, Vol. No. 2 pp. 41-53

Guloba, Madina. Kilimani, Nicholas \& Nabiddo, Winnie. (2010). Impact of ChinaAfrica aid relation; the case of Uganda. African Economic Research Consortium (AERC).

Greber, S Araya. (2012). Interdependence in China-Africa Aid Relations, Master thesis from University of Lund.

Rupp, S. (2008). Africa and China: Engaging Postcolonial Interdependence. In: Rotberg, R.I (ed.) CHINA into AFRICA: Trade, Aid, and Influence. Washington D.C.: Brooking Institution Press., p.65 - 86.

Shelton, G (2004) "Trading with the Dragon; Prospects for a China-South Africa FTA". South Africa Journal of International Afairs, 11 (2); page 59 - 71.'

Taylor, Ian (2004). The "all-weather friend"? Sino-African interaction in the twenty - first century" in Taylor,I \& William,O (eds.) 2004. Africa in International Politics External involvement on the continent. London: Routledge

Wang, A. et al. (2010) China-Africa Political and Economic Relations in the 21st Century: An analysis of China's new Involvement into Africa. (online) Available at: http://114.113.29.168/bslw/2010107745.pdf. (Accessed: 22/05/ 2013).

Yin, R. K. (2003). Case study research: Design and methods (3rd ed.). Thousand Oaks, CA: Sage.

Creswell, J. W., and Asmussen K. J. (1995). Campus response to a student gunman. Journal of Higher Education. 66, 575-59 